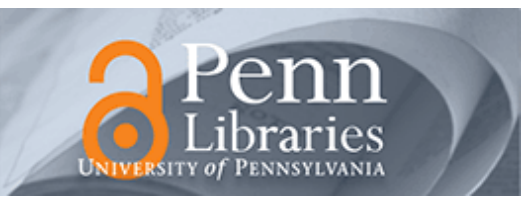

University of Pennsylvania ScholarlyCommons

\title{
Chemokine Expression Is Upregulated in Chondrocytes in Diabetic Fracture Healing
}

Jazia Alblowi

Chen Tian

University of Pennsylvania

Rayyan A. Kayal

Erin McKenzie

Yugal Behl

See next page for additional authors

Follow this and additional works at: https://repository.upenn.edu/dental_papers

Part of the Amino Acids, Peptides, and Proteins Commons, Dentistry Commons, Endocrinology, Diabetes, and Metabolism Commons, and the Osteopathic Medicine and Osteopathy Commons

\section{Recommended Citation}

Alblowi, J., Tian, C., Kayal, R. A., McKenzie, E., Behl, Y., Gerstenfeld, L., Einhorn, T. A., \& Graves, D. T. (2013). Chemokine Expression Is Upregulated in Chondrocytes in Diabetic Fracture Healing. Bone, 53 (1), 294-300. http://dx.doi.org/10.1016/j.bone.2012.12.006 


\title{
Chemokine Expression Is Upregulated in Chondrocytes in Diabetic Fracture Healing
}

\begin{abstract}
Chemokines are thought to play an important role in several aspects of bone metabolism including the recruitment of leukocytes and the formation of osteoclasts. We investigated the impact of diabetes on chemokine expression in normal and diabetic fracture healing. Fracture of the femur was performed in streptozotocin-induced diabetic and matched normoglycemic control mice. Microarray analysis was carried out and chemokine mRNA levels in vivo were assessed. CCL4 were examined in fracture calluses by immunohistochemistry and the role of TNF in diabetes-enhanced expression was investigated by treatment of animals with the TNF-specific inhibitor, pegsunercept. In vitro studies were conducted with ATDC5 chondrocytes. Diabetes significantly upregulated mRNA levels of several chemokines in vivo including CCL4, CCL8, CCL6, CCL11, CCL20, CCL24, CXCL2, CXCL5 and chemokine receptors CCR5 and CXCR4. Chondrocytes were identified as a significant source of CCL4 and its expression in diabetic fractures was dependent on TNF $(P<0.05)$. TNF- $\alpha$ significantly increased mRNA levels of several chemokines in vitro which were knocked down with FOXO1 siRNA $(P<0.05)$. CCL4 expression at the mRNA and proteins levels was induced by FOXO1 over-expression and reduced by FOXO1 knockdown. The current studies point to the importance of TNF- $\alpha$ as a mechanism for diabetes enhanced chemokine expression by chondrocytes, which may contribute to the accelerated loss of cartilage observed in diabetic fracture healing. Moreover, in vitro results point to FOXO1 as a potentially important transcription factor in mediating this effect.
\end{abstract}

\section{Keywords}

Animals, Chemokines, Chondrocytes, Diabetes Mellitus, Experimental, Fracture Healing, Immunohistochemistry, Mice, RNA Interference, RNA, Messenger, Up-Regulation

\section{Disciplines}

Amino Acids, Peptides, and Proteins | Dentistry | Endocrinology, Diabetes, and Metabolism | Osteopathic Medicine and Osteopathy

\section{Author(s)}

Jazia Alblowi, Chen Tian, Rayyan A. Kayal, Erin McKenzie, Yugal Behl, Louis Gerstenfeld, Thomas A. Einhorn, and Dana T. Graves 
Published in final edited form as:

Bone. 2013 March ; 53(1): 294-300. doi:10.1016/j.bone.2012.12.006.

\title{
Chemokine Expression is Upregulated in Chondrocytes in Diabetic Fracture Healing
}

\author{
Jazia Alblowi ${ }^{1}$, Chen Tiann ${ }^{2}$, Michelle F. Siqueira ${ }^{3}$, Rayyan Kayal ${ }^{1}$, Erin McKenzie ${ }^{3}$, Yugal \\ Behl $^{3}$, Louis Gerstenfeld ${ }^{4}$, Thomas A. Einhorn ${ }^{4}$, and Dana T. Graves ${ }^{2}$ \\ ${ }^{1}$ Faculty of Dentistry, King Abdulaziz University, Jeddah, Saudi Arabia \\ ${ }^{2}$ Department of Periodontology and Oral Biology, University of Pennsylvania School of Dental \\ Medicine, Philadelphia, PA; Department of Periodontics, University of Pennsylvania School of \\ Dental Medicine, Philadelphia, PA \\ ${ }^{3}$ Boston University School of Dental Medicine, Boston, MA \\ ${ }^{4}$ Department of Orthopedic Surgery, Boston University School of Medicine
}

\section{Abstract}

Chemokines are thought to play an important role in several aspects of bone metabolism including the recruitment of leukocytes and the formation of osteoclasts. We investigated the impact of diabetes on chemokine expression in normal and diabetic fracture healing. Fracture of the femur was performed in streptozotocin-induced diabetic and matched normoglycemic control mice. Microarray analysis was carried out and chemokine mRNA levels in vivo were assessed. CCL4 were examined in fracture calluses by immunohistochemistry and the role of TNF in diabetesenhanced expression was investigated by treatment of animals with the TNF-specific inhibitor, pegsunercept. In vitro studies were conducted with ATDC5 chondrocytes. Diabetes significantly upregulated mRNA levels of several chemokines in vivo including CCL4, CCL8, CCL6, CCL11, CCL20, CCL24, CXCL2, CXCL5 and chemokine receptors CCR5 and CXCR4. Chondrocytes were identified as a significant source of CCL4 and its expression in diabetic fractures was dependent on TNF in diabetic fractures $(\mathrm{P}<0.05)$. TNF-a significantly increased mRNA levels of several chemokines in vitro which were knocked down with FOXO1 siRNA $(\mathrm{P}<0.05)$. CCL4 expression at the mRNA and proteins levels was induced by FOXO1 over-expression and reduced by FOXO1 knockdown. The current studies point to the importance of TNF-a as a mechanism for diabetes enhanced chemokine expression by chondrocytes, which may contribute to the accelerated loss of cartilage observed in diabetic fracture healing. Moreover, in vitro results point to FOXO1 as a potentially important transcription factor in mediating this effect.

\section{Introduction}

Chemokines are small (8-11 kDa) chemotactic cytokines secreted by many cell types in response to growth factors, inflammatory cytokines, and cancer cells [1]. Chemokines are classified into two major subfamilies by their $\mathrm{N}$ terminal cysteines, $\mathrm{CXC}, \mathrm{CC}$, and two

\footnotetext{
(c) 2012 Elsevier Inc. All rights reserved.

Corresponding author: Dr. Dana T. Graves, Department of Periodontics, University of Pennsylvania School of Dental Medicine, Philadelphia, PA. 215-898-9068. dtgraves@ dental.upenn.edu.

Publisher's Disclaimer: This is a PDF file of an unedited manuscript that has been accepted for publication. As a service to our customers we are providing this early version of the manuscript. The manuscript will undergo copyediting, typesetting, and review of the resulting proof before it is published in its final citable form. Please note that during the production process errorsmaybe discovered which could affect the content, and all legal disclaimers that apply to the journal pertain.
} 
minor families, $\mathrm{C}$ and $\mathrm{CX} 3 \mathrm{C}$. Some chemokines interact with a single high affinity chemokine receptor while others bind multiple chemokine receptors [1].

Osteoclasts originate from hematopoietic precursors of the monocyte-macrophage lineage that reside within the bone marrow. Chemokines that are chemotactic for cells of this lineage are thought to be important in trafficking of osteoclast precursors and to modulate the lifespan of osteoclasts [2,3]. A number of chemokines have been reported to recruit osteoclast precursors or stimulate osteoclastogenesis including CCL2, CCL3, CCL4, CXCL8 and CXCL12 [4]. In conditions where there is increased bone resorption these chemokines are elevated such as arthritis, osteolytic bone disease of multiple myeloma and periodontal disease [5-8]. CCL3 and CCL4 are constitutively secreted by multiple myeloma cells and are linked to the development of osteolytic bone lesions [9]. CCL3-positive cells are increased with increasing severity of periodontal disease and MCP-1/CCL2, CCL3, and CCL4 are present in periapical granulomas [10]. The capacity of CCL3 to promote bone resorption has been shown to occur through RANKL dependent and RANKL independent pathways and has recently been linked to suppression of coupled bone formation in leukemia [11]. Interestingly, RANKL also induces the production chemokines, suggesting an amplification loop during recruitment of precursors and differentiation of osteoclasts [12]. Elevated levels of SDF1/CXCL12 in the synovial and bone tissue of patients with rheumatoid arthritis are correlated to pathological bone loss caused by an increase in the recruitment and activation of osteoclasts at sites of local inflammation [13]. Collectively, these studies indicate a relationship between chemokine expression and osteoclastic bone resorption.

We have reported previously that impaired diabetic fracture healing is associated with elevated TNF- $\alpha$ levels and osteoclast numbers [14]. Moreover, inhibition of TNF decreases diabetes-enhanced cartilage degradation and osteoclastogenesis $[15,16]$. In the current study we examined chemokine expression in diabetic fracture repair and the role of the FOXO1 transcription in mediating TNF induced chemokine and chemokine receptor mRNA levels in vitro. The results show that diabetic fracture healing is associated with elevated levels of chemokines. CCL3 was examined by immunohistochemistry and shown to be expressed at higher levels in diabetic fractures, predominantly in hypertrophic chondrocytes in a TNF dependent manner. In vitro experiments using BMP stimulated ATDC5 and C3H10T1/2 cells with a hypertrophic chondrocyte phenotype demonstrated that FOXO1 knockdown decreased the expression of chemokines that were upregulated by TNF stimulation. Due to the capacity of chemokines to enhance inflammation through stimulation and activation of leukocytes and osteoclastogenesis, the results point to the possible involvement of chemokines in impaired diabetic fracture repair.

\section{Material and Methods}

\section{Induction of Type 1 Diabetes and Femoral fracture}

All experiments were conducted in conformity with Federal and USDA guidelines and had Institutional Animal Care \& Use Committee (IACUC). Eight week old male CD-1 mice were purchased from Charles River Laboratories (Wilmington, MA). Diabetes was induced by intraperitoneal injection of streptozotocin ( $40 \mathrm{mg} / \mathrm{kg}$ ) (Sigma, St. Louis, MO) daily for 5 days [17]. A group of mice were treated with vehicle alone (10 $\mathrm{mM}$ citrate). Evaluation of blood glucose levels was performed using blood samples taken from the tail (Accu-Chek, Roche Diagnostics, Indianapolis, IN). When the blood glucose levels exceeded $250 \mathrm{mg} / \mathrm{dl}$ mice were considered diabetic. Transverse closed fractures of the femur were performed in diabetic mice that were hyperglycemic for 3 weeks as described in [14, 17-19]. Fixation was achieved by placement of a 27 gauge spinal needle into the marrow cavity of the femur and fracture was induced by blunt trauma. Intraperitoneal injection of TNF inhibitor 
pegsunercept $(4 \mathrm{mg} / \mathrm{kg})$ was undertaken starting on day 10 post fracture and repeated every 3 days until euthanasia. Animals were euthanized at the 10 day and 16 day time points after fracture. Glycosylated hemoglobin level was measured by Glyco-tek affinity chromatography (Helena Laboratories, Beaumont, TX) at the time of euthanasia. Results showed no significant differences between pegsunercept treated and vehicle treated groups (data not shown).

\section{Histology and Immunohistochemistry}

Fixation of the specimens in cold $4 \%$ paraformaldehyde was performed for 72 hours followed by decalcification in cold Immunocal (Decal Corporation, Congers, NY) for 2 weeks. Embedding in paraffin and sectioning were performed as described in [18]. Deparaffinization and antigen retrieval was performed in $10 \mathrm{mM}$ sodium citrate (pH 6.0) at 95 degree for 5 minutes. Specimens then were incubated with 3\% hydrogen peroxide for 15 minutes at room temperature. Blocking was done using avidin biotin blocking system (Vector Laboratories, Burlingame, $\mathrm{CA}$ ) and non-immune serum matching the secondary antibody. Incubation with anti MIP-1 $\beta / C C L 4$ antibody purchased from (R\&D System) or matched non-specific IgG at $4 \mathrm{C}$ degree overnight was carried out, followed by several washing and incubation with biotin labeled secondary antibody (Santa Cruz Biotechnology, Santa Cruz, CA). Detection and visualization were done using an avidin-biotin kit from Vector Laboratories, and chromogen 3, 3'-diaminobenzidine (Zymed Laboratories Inc, South San Francisco, CA) and counterstained with hematoxylin. The percentage of expression of MIP-1 $\beta$ /CCL4in different cell types in the callus was done taking 20 representative fields per callus using the scale shown in Supplemental Table 1. There were 6-7 samples per group. Analysis was done blindly by one examiner with the results confirmed by second examiner.

\section{mRNA Profiling of Fracture Calluses}

Fracture calluses from each group were collected, soft tissue was gently removed and specimens were snap frozen in liquid nitrogen. RNA extraction from each callus was performed using Trizol (Life Technologies, Rockville, MD) and the extracted RNA was purified using RNAeasy MinElute cleanup kit (Qiagen, Valencia, CA). mRNA profiling was carried out using a PGA Mouse v1.1 array as we have previously described [15, 20]. Preparation of microarray probe and reading of fluorescent intensity were performed by the Massachusetts General Hospital Microarray Core Facility (Cambridge, MA). Data represent the mean of four replicates. The data related to chemokines and their receptors were analyzed and the difference in expression between diabetic and normoglycemic was analyzed as fold change.

\section{FOXO1 RNAi and Overexpression}

ATDC5 were cultured as we have previously described [15]. Cells were then plated in 6 well plates and when reached 70\% confluency were transfected with 5nM ON-TARGETplus SMARTpool siRNAs against FOXO1 or control siRNA (Dharmacon, Chicago, IL) with Lipofectamine RNAiMAX (Invitrogen, Carlsbad, CA) in media supplemented with FBS $(0.25 \%)$ as we have previously described [15]. Supernatant was collected and total RNA was extracted. Real time PCR was performed using probes and primer sets designed by the Universal Probe Library Assay Design Center (Roche, Indianapolis). Results were normalized by reference to mRNA levels of the housekeeping gene L32. mRNA profiling was carried out with a focused Chemokines and Receptors PCR Microarray (SA Biosciences, Valencia, CA) according to the manufacturer's instructions using the PCR Array Data Analysis web portal (SA Biosciences). Data represent the mean values obtained from three separate replicates. For overexpression of FOXO1 constructs containing the full length human FOXO1, constitutively active FOXO1AAA that was mutated at the Akt 
phosphorylation sites or vector containing green fluorescent protein (GFP) were purchased from Addgene (Cambridge, MA). Transfections were performed using SuperFect (Qiagen). Cell lysates were examined for mRNA levels of CCL3 and CCL4 and supernatants were examined for protein level of CCL4 by ELISA (R\&D Systems, Minneapolis, MN).

\section{Statistical Analysis}

Data are presented as mean values \pm SEM. Statistical significance between multiple groups for a given parameter was analyzed by ANOVA with Scheffe's post-hoc test. Results from immunohistochemistry using a scale from 0 to 5 were analyzed using Kruskal-Wallis nonparametric analysis of multiple groups and the Mann-Whitney post-hoc test. RNAi experiments and FOXO1 over-expression experiments were performed two to three times with similar results. In microarray data, statistical difference between diabetic and normoglycemic groups were evaluated using Student's $T$ test $(\mathrm{p}<0.05)$.

\section{Results}

To investigate the effect of diabetes on the expression of chemokines and chemokine receptors, microarray analysis was carried out using RNA samples from fracture calluses focusing on the stage of transition from cartilage to bone, day 16 following fracture. The difference in gene expression between diabetic and normoglycemic groups was considered significant if the $\mathrm{P}$ value was less than 0.05 . Diabetic specimens showed upregulation of several chemokines and their receptors (Table 1) with a significant 1.28 to 5.71 fold increase in mRNA levels in more than 10 chemokines and receptors in diabetic compared to normoglycemic mice $(\mathrm{p}<0.05)$. Several belonged to the $\mathrm{CC}$ subfamily of chemokines such as CCL4, CCL8, CCL6, CCL11, CCL20, CCL24 and the CC chemokine receptor CCR5 receptor. There was also a significant increase in the expression of $\mathrm{CXC}$ chemokines in the fracture sites of diabetic mice in vivo when compared to normoglycemic mice such as CXCL2, CXCL5 and the CXC chemokine receptor CXCR4.

Since CCL4 expression has been linked to osteoclastogenesis in inflammatory bone diseases [21] and was significantly up-regulated in the fracture calluses (Table 2) we further examined its expression in fracture calluses by immunohistochemistry. The percentage of CCL4 positive hypertrophic and proliferative chondrocytes was assessed in Figures 1A and $1 \mathrm{~B}$, respectively. In the normoglycemic group there was little increase in the expression of CCL4 in hypertrophic chondrocytes from day 10 to day 16, while there was in the diabetic group $(\mathrm{P}<0.05$; Figure 1). The increase in the diabetic group was blocked by inhibition of TNF $(\mathrm{P}<0.05)$. The percent hypertrophic chondrocytes that expressed CCL4 was higher than proliferative chondrocytes in diabetic and normoglycemic groups on both days 10 and 16 $(\mathrm{P}<0.05$; Figure 1A compared to 1B). Examples of CCL4 positive chondrocytes are shown in Supplemental Figure 1. Semi-quantitative analysis was also performed to examine the relative expression of CCL4 in various cell types including proliferative chondrocytes, hypertrophic chondrocytes, osteoblasts/mesenchymal cells in developing bone and fibroblastic cells in the callus capsule using the scale shown in Supplemental Table 1. Overall hypertrophic chondrocytes had the highest level of CCL4 immunopositive cells followed by proliferative chondrocytes, osteoblastic/mesenchymal cells in the developing bone, and lastly, fibroblastic cells in the capsule (Figure 2). There was no difference between diabetic and normoglycemic mice in the percent positive CCL4 osteoblasts/ mesenchymal cells or fibroblastic cells and the specific inhibition of TNF had no effect $(\mathrm{P}>0.05)$.

In vitro studies were carried out to investigate a potential mechanism by which TNF may stimulate chemokines in ATDC5 chondrocytes. CCL4 was examined because of results obtained in Fig 1 and CCL3 was examined because of its role in promoting 
osteoclastogenesis [22]. Cells were transfected with FOXO1 siRNA or scrambled siRNA and stimulated with TNF-a $(20 \mathrm{ng} / \mathrm{ml})$. TNF induced a 4 fold increase in CCL3 and CCL4 mRNA levels. FOXO1 siRNA had little effect on CCL3 basal mRNA levels but did block almost all of the increase stimulated by TNF-a $(\mathrm{P}<0.05)$ (Fig 3). Under basal conditions FOXO1 knockdown reduced CCL4 mRNA and protein levels by approximately $50 \%$. FOXO1 siRNA blocked almost all of the increase in CCL4 mRNA stimulated by TNF-a. TNF- $a$ induced a 2 fold increase of CCLR at the protein level, which was blocked by FOXO1 knockdown ( $\mathrm{P}<0.05$; Figure 3C). In contrast scrambled siRNA had no effect on CCL3 or CL4 expression ( $\mathrm{P}>0.05)$.

Additional experiments were carried out examining ATDC5 chondrocytes transfected with the full length human FOXO1 or FOXO1AAA that has been mutated so that it is constitutively active [23]. Transfection with constitutively active FOXO1AAA induced 3 fold increase in CCL3 mRNA and FOXO1 and FOXO1AAA induced a 3 fold increase in CCL4 mRNA levels. When released CCL4 was measured at the protein level FOXO1 induced a $50 \%$ increase and FOXO1AAA a $100 \%$ increase. Transfection with vector containing green fluorescent protein had no effect.

To further explore the role of TNF- $a$ in chemokine induction in ATDC5 chondrocytes, in vitro experiments were performed using a focused PCR array (Table 2). TNF-a significantly enhanced mRNA levels of 14 out of 25 chemokines in the array $(56 \%)$ with the degree of upregulation ranging from 6 to greater than 1000 fold $(\mathrm{P}<0.05)$ (Table 2). In every case, FOXO1 knockdown significantly $(\mathrm{P}<0.05)$ blunted the increase stimulated TNF-a (Table 2). In addition 19 chemokine receptors were examined for increased expression by TNF- $\alpha$ and regulation by FOXO1. Two of these were significantly increased by TNF and two others just missed being significant. mRNA levels for CCR1, CCRL2 and CCR4 were significantly reduced by FOXO1. Other inflammatory genes and morphogenetic proteins genes included in the array were also upregulated by TNF stimulation by at least 6 fold (Table 2B; $\mathrm{P} \unlhd 0.05$ ). In each case the TNF mediated increase was reduced by FOXO1 knockdown. These results point to the overall importance of TNF in induction of inflammatory molecules including chemotactic cytokines and their receptors in chondrocytes and the possible role of FOXO1 in mediating the effect of TNF stimulation.

\section{Discussion}

Diabetes has a significant impact on fracture healing and increases the inflammatory environment at the fracture site $[14,24,25]$. By mRNA profiling we show here a potentially unrecognized mechanism for diabetes impaired fracture healing; enhanced expression of chemokines during the transition from cartilage to bone in the healing fracture callus. Diabetic fracture sites had significant upregulation of several chemokines and receptors, CCL4, CCL8, CCL6, CCL11, CCL20, CCL24, CXCL2, CXCL5 and chemokine receptors CCR5 and CXCR4. In vitro TNF-a stimulated mRNA levels of several chemokines in chondrocytes that were also enhanced by diabetes in vivo including CCL4, CCL8, CCL20, CXCL2 and CXCL5. Each of these is chemotactic for leukocyte subsets including lymphocytes, monocytes and PMNs and to be produced by chondrocytes [26-28]. The induction of chemokines by TNF- $a$ is consistent with previous findings that the hyperinflammatory response in diabetic fracture healing is caused in part, by the elevated levels of TNF-a $[15,16]$. Moreover, CCL4 was shown by immunohistochemistry to be induced in hypertrophic chondrocytes in diabetic fracture sites by a TNF-dependent mechanism. Two chemokines upregulated by diabetes in vivo CCL6 and CCL11 were not regulated by TNF in vitro, suggesting that they may be regulated by other factors present in diabetic calluses or primarily expressed in cells other than chondrocytes. Compared to chemokine ligands there was less overlap between chemokine receptors elevated in diabetic 
fracture calluses and regulation of chemokine receptors by TNF in vitro. This may reflect the relatively few chemokine receptors that were included in the in vivo microarray or expression by cells other than chondrocytes. However, expression of CCR1 and CCR4 have been found in chondrocytes $[29,30]$ and were regulated by TNF in a FOXO1 dependent manner.

In summary, we report here that diabetic fracture calluses are characterized by enhanced chemokine expression and at least in some cases, chondrocytes are likely to be an important source as shown for CCL4. The expression of chemokines could contribute to the accelerated loss of cartilage noted in diabetic fracture calluses $[14,17]$ by enhancing the level of inflammation through recruitment of leukocyte subsets or through the recruitment of osteoclast precursors and osteoclast formation [26]. The potential importance of inflammatory mediators is underscored by the rapid loss of cartilage under conditions where inflammation is enhanced such as diabetes [14, 31]. Conversely, when inflammation is suppressed by genetic deletion of TNF receptors, degradation of cartilage is delayed [32]. This may be significant since cartilage forms the anlagen for endochondral bone formation. In addition, chemokines have other potential effects such as the production of degradative enzymes and autocrine stimulation of osteoclasts that may enhance apoptosis [26, 33]. Thus, it is possible that dysregation in diabetes leads to elevated production of cytokines such as TNF- $\alpha$, which in turn induces the expression of chemokines that amplify the level of inflammation and catabolic effect of diabetes on diabetic fracture healing.

Chemokines and their receptors have been found to participate in diseases involving bone and cartilage degradation such as osteoarthritis and rheumatoid arthritis and osteolytic lesions from various pathologies $[4,34,35]$. Thus, it is possible that chemokine production by chondrocytes has an autocrine or paracrine role in including an effect on inflammation, apoptosis, production of degradative enzymes and formation of osteoclasts [36].

Experiments with chemokine inhibition at the time of cartilage degradation would be needed to definitively establish the role of chemokines in the transition from cartilage to bone during fracture healing.

\section{Supplementary Material}

Refer to Web version on PubMed Central for supplementary material.

\section{Acknowledgments}

We would like to thank Sunitha Batchu for help in preparing this manuscript. The work was supported by NIH grant R01AR060055.

\section{Literature Cited}

1. Bonecchi R, Galliera E, Borroni EM, Corsi MM, Locati M, Mantovani A. Chemokines and chemokine receptors: an overview. Front Biosci. 2009; 14:540-51.

2. Bendre MS, Montague DC, Peery T, Akel NS, Gaddy D, Suva LJ. Interleukin-8 stimulation of osteoclastogenesis and bone resorption is a mechanism for the increased osteolysis of metastatic bone disease. Bone. 2003; 33:28-37. [PubMed: 12919697]

3. Wright LM, Maloney W, Yu X, Kindle L, Collin-Osdoby P, Osdoby P. Stromal cell-derived factor-1 binding to its chemokine receptor CXCR4 on precursor cells promotes the chemotactic recruitment, development and survival of human osteoclasts. Bone. 2005; 36:840-53. [PubMed: 15794931]

4. Silva TA, Garlet GP, Fukada SY, Silva JS, Cunha FQ. Chemokines in oral inflammatory diseases: apical periodontitis and periodontal disease. J Dent Res. 2007; 86:306-19. [PubMed: 17384024] 
5. Giuliani N, Lisignoli G, Colla S, Lazzaretti M, Storti P, Mancini C, Bonomini S, Manferdini C, Codeluppi K, Facchini A, Rizzoli V. CC-Chemokine ligand 20/macrophage inflammatory protein-3alpha and CC-chemokine receptor 6 are overexpressed in myeloma microenvironment related to osteolytic bone lesions. Cancer Res. 2008; 68:6840-50. [PubMed: 18703490]

6. Maruotti N, Grano M, Colucci S, d'Onofrio F, Cantatore FP. Osteoclastogenesis and arthritis. Clin Exp Med. 2011; 11:137-45. [PubMed: 21069419]

7. Repeke CE, Ferreira SB Jr, Claudino M, Silveira EM, de Assis GF, Avila-Campos MJ, Silva JS, Garlet GP. Evidences of the cooperative role of the chemokines CCL3, CCL4 and CCL5 and its receptors CCR1+ and CCR5+ in RANKL+ cell migration throughout experimental periodontitis in mice. Bone. 2010; 46:1122-30. [PubMed: 20053385]

8. Haaber J, Abildgaard N, Knudsen LM, Dahl IM, Lodahl M, Thomassen M, Kerndrup GB, Rasmussen T. Myeloma cell expression of 10 candidate genes for osteolytic bone disease. Only overexpression of DKK1 correlates with clinical bone involvement at diagnosis. Br J Haematol. 2008; 140:25-35. [PubMed: 18005268]

9. Roodman GD. Mechanisms of bone lesions in multiple myeloma and lymphoma. Cancer. 1997; 80:1557-63. [PubMed: 9362422]

10. Kabashima H, Yoneda M, Nagata K, Hirofuji T, Ishihara Y, Yamashita M, Maeda K. The presence of chemokine receptor (CCR5, CXCR3, CCR3)-positive cells and chemokine (MCP1, MIP-1alpha, MIP-1beta, IP-10)-positive cells in human periapical granulomas. Cytokine. 2001; 16:62-6. [PubMed: 11683586]

11. Frisch BJ, Ashton JM, Xing L, Becker MW, Jordan CT, Calvi LM. Functional inhibition of osteoblastic cells in an in vivo mouse model of myeloid leukemia. Blood. 2012; 119:540-50. [PubMed: 21957195]

12. Kim MS, Day CJ, Selinger CI, Magno CL, Stephens SR, Morrison NA. MCP-1-induced human osteoclast-like cells are tartrate-resistant acid phosphatase, NFATc1, and calcitonin receptorpositive but require receptor activator of NFkappaB ligand for bone resorption. J Biol Chem. 2006; 281:1274-85. [PubMed: 16280328]

13. Grassi F, Cristino S, Toneguzzi S, Piacentini A, Facchini A, Lisignoli G. CXCL12 chemokine upregulates bone resorption and MMP-9 release by human osteoclasts: CXCL12 levels are increased in synovial and bone tissue of rheumatoid arthritis patients. J Cell Physiol. 2004; 199:244-51. [PubMed: 15040007]

14. Kayal RA, Tsatsas D, Bauer MA, Allen B, Al-Sebaei MO, Kakar S, Leone CW, Morgan EF, Gerstenfeld LC, Einhorn TA, Graves DT. Diminished bone formation during diabetic fracture healing is related to the premature resorption of cartilage associated with increased osteoclast activity. J Bone Miner Res. 2007; 22:560-8. [PubMed: 17243865]

15. Kayal RA, Siqueira M, Alblowi J, McLean J, Krothapalli N, Faibish D, Einhorn TA, Gerstenfeld LC, Graves DT. TNF-alpha mediates diabetes-enhanced chondrocyte apoptosis during fracture healing and stimulates chondrocyte apoptosis Through FOXO1. J Bone Miner Res. 2010; 25:1604-1615. [PubMed: 20200974]

16. Alblowi J, Kayal RA, Siqueria M, McKenzie E, Krothapalli N, McLean J, Conn J, Nikolajczyk B, Einhorn TA, Gerstenfeld L, Graves DT. High levels of tumor necrosis factor-alpha contribute to accelerated loss of cartilage in diabetic fracture healing. Am J Pathol. 2009; 175:1574-85. [PubMed: 19745063]

17. Kayal RA, Alblowi J, McKenzie E, Krothapalli N, Silkman L, Gerstenfeld L, Einhorn TA, Graves DT. Diabetes causes the accelerated loss of cartilage during fracture repair which is reversed by insulin treatment. Bone. 2009; 44:357-63. [PubMed: 19010456]

18. Gerstenfeld LC, Wronski TJ, Hollinger JO, Einhorn TA. Application of histomorphometric methods to the study of bone repair. J Bone Miner Res. 2005; 20:1715-22. [PubMed: 16160729]

19. Gerstenfeld LC, Alkhiary YM, Krall EA, Nicholls FH, Stapleton SN, Fitch JL, Bauer M, Kayal R, Graves DT, Jepsen KJ, Einhorn TA. Three-dimensional reconstruction of fracture callus morphogenesis. J Histochem Cytochem. 2006; 54:1215-28. [PubMed: 16864894]

20. Wang K, Vishwanath P, Eichler GS, Al-Sebaei MO, Edgar CM, Einhorn TA, Smith TF, Gerstenfeld LC. Analysis of fracture healing by large-scale transcriptional profile identified temporal relationships between metalloproteinase and ADAMTS mRNA expression. Matrix Biol. 2006; 25:271-81. [PubMed: 16584876] 
21. Abe M, Hiura K, Wilde J, Moriyama K, Hashimoto T, Ozaki S, Wakatsuki S, Kosaka M, Kido S, Inoue D, Matsumoto T. Role for macrophage inflammatory protein (MIP)-1alpha and MIP-1beta in the development of osteolytic lesions in multiple myeloma. Blood. 2002; 100:2195-202. [PubMed: 12200385]

22. Han JH, Choi SJ, Kurihara N, Koide M, Oba Y, Roodman GD. Macrophage inflammatory protein-1alpha is an osteoclastogenic factor in myeloma that is independent of receptor activator of nuclear factor kappaB ligand. Blood. 2001; 97:3349-53. [PubMed: 11369623]

23. Ramaswamy S, Nakamura N, Sansal I, Bergeron L, Sellers WR. A novel mechanism of gene regulation and tumor suppression by the transcription factor FKHR. Cancer Cell. 2002; 2:81-91. [PubMed: 12150827]

24. Loder R. The influence of diabetes mellitus on the healing of closed fractures. Clin Orthop. 1988; (232):210-6. Review. [PubMed: 3289812]

25. Herbsman H, Powers J, Hirschman A, Shaftan G. Retardation of fracture healing in experimental diabetes. J Surg Res. 1968; 8:424-431. [PubMed: 5673338]

26. Szekanecz Z, Vegvari A, Szabo Z, Koch AE. Chemokines and chemokine receptors in arthritis. Front Biosci (Schol Ed). 2010; 2:153-67. [PubMed: 20036936]

27. Kasama T, Strieter RM, Lukacs NW, Lincoln PM, Burdick MD, Kunkel SL. Interleukin-10 expression and chemokine regulation during the evolution of murine type II collagen-induced arthritis. J Clin Invest. 1995; 95:2868-76. [PubMed: 7769128]

28. Sandell LJ, Xing X, Franz C, Davies S, Chang LW, Patra D. Exuberant expression of chemokine genes by adult human articular chondrocytes in response to IL-1beta. Osteoarthritis Cartilage. 2008; 16:1560-71. [PubMed: 18565769]

29. Silvestri T, Meliconi R, Pulsatelli L, Dolzani P, Zizzi F, Frizziero L, Borzi RM, Facchini A. Downmodulation of chemokine receptor cartilage expression in inflammatory arthritis. Rheumatology (Oxford). 2003; 42:14-8. [PubMed: 12509607]

30. Djouad F, Delorme B, Maurice M, Bony C, Apparailly F, Louis-Plence P, Canovas F, Charbord P, Noel D, Jorgensen C. Microenvironmental changes during differentiation of mesenchymal stem cells towards chondrocytes. Arthritis Res Ther. 2007; 9:R33. [PubMed: 17391539]

31. Ogasawara A, Nakajima A, Nakajima F, Goto K, Yamazaki M. Molecular basis for affected cartilage formation and bone union in fracture healing of the streptozotocin-induced diabetic rat. Bone. 2008; 43:832-9. [PubMed: 18725334]

32. Gerstenfeld LC, Cho TJ, Kon T, Aizawa T, Tsay A, Fitch J, Barnes GL, Graves DT, Einhorn TA. Impaired fracture healing in the absence of TNF-alpha signaling: the role of TNF-alpha in endochondral cartilage resorption. J Bone Miner Res. 2003; 18:1584-92. [PubMed: 12968667]

33. James CG, Appleton CT, Ulici V, Underhill TM, Beier F. Microarray analyses of gene expression during chondrocyte differentiation identifies novel regulators of hypertrophy. Mol Biol Cell. 2005; 16:5316-33. [PubMed: 16135533]

34. Borzi RM, Mazzetti I, Macor S, Silvestri T, Bassi A, Cattini L, Facchini A. Flow cytometric analysis of intracellular chemokines in chondrocytes in vivo: constitutive expression and enhancement in osteoarthritis and rheumatoid arthritis. FEBS Lett. 1999; 455:238-42. [PubMed: 10437780]

35. Vergunst CE, van de Sande MG, Lebre MC, Tak PP. The role of chemokines in rheumatoid arthritis and osteoarthritis. Scand J Rheumatol. 2005; 34:415-25. [PubMed: 16393761]

36. Goldring MB, Otero M. Inflammation in osteoarthritis. Curr Opin Rheumatol. 2011; 23:471-8. [PubMed: 21788902] 


\section{Highlights}

- Diabetes enhances chemokine expression in Fracture Healing

- Hypertrophic chondrocytes express chemokines during fracture healing in a TNF dependent manner

- TNF induced chemokine expression in chondrocytes is mediated by transcription factor FOXO1 
A

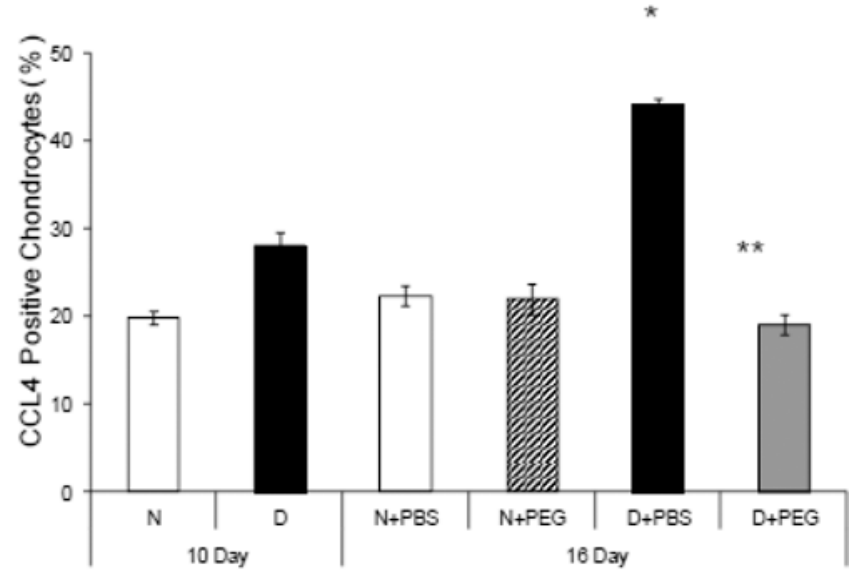

B

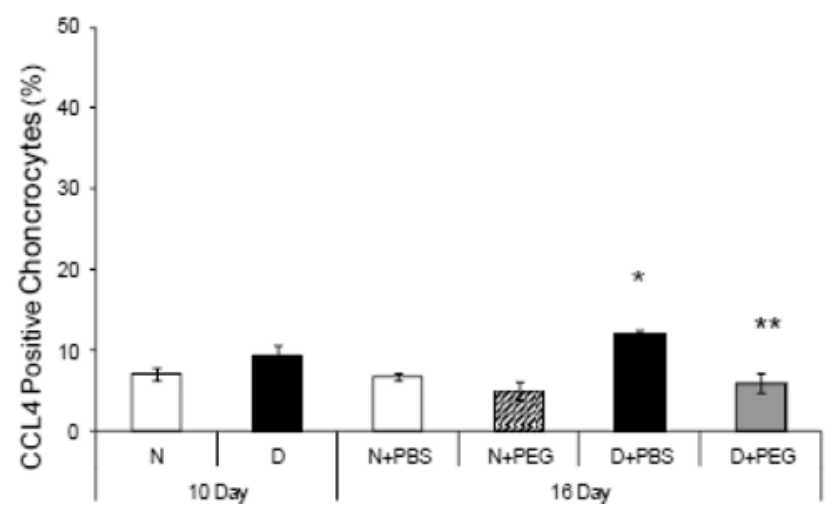

Figure 1. Chondrocytes express enhanced CCL4 expression in diabetic fractures that is TNF dependent

Femoral fractures were induced in normoglycemic $(\mathrm{N})$ or diabetic $(\mathrm{D})$ mice which were treated with the TNF-specific inhibitor, pegsunercept (PEG) or PBS alone (PBS) starting on day 10. Transverse sections were examined by immunohistochemistry for expression of CCL4. Figure 1A: The percent hypertrophic chondrocytes that expressed CCL4. Figure 1B: The percent proliferative chondrocytes that expressed CCL4.* indicate significant differences between normal and diabetic groups $(\mathrm{P}<0.05)$. ** Indicates differences between diabetic and PEG treated groups $(\mathrm{P}<0.05)$. 

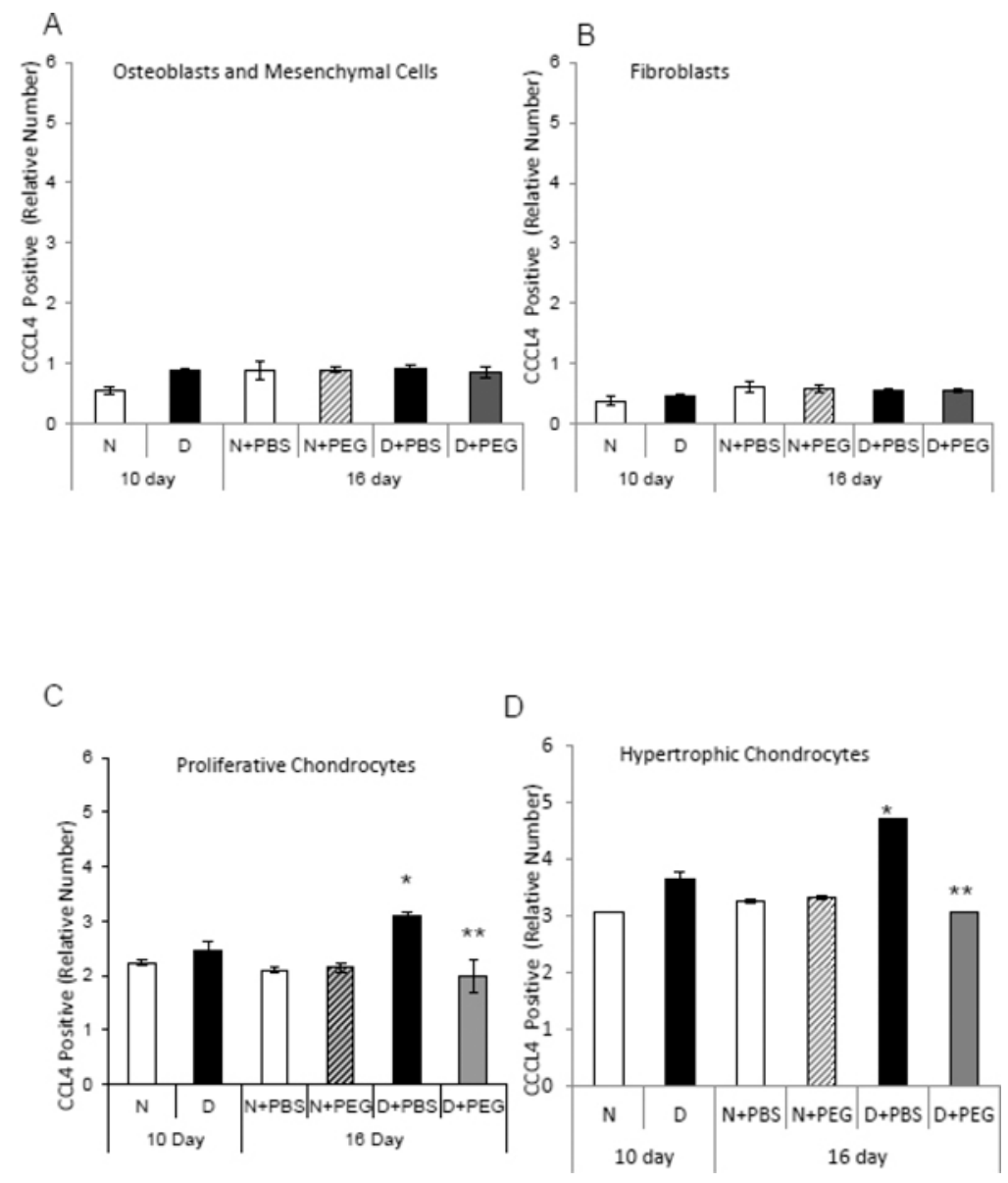

Figure 2. CCL4 expression occurs preferentially in hypertrophic chondrocytes Sections from fracture calluses were examined by immunohistochemistry for CCL4 expression. The relative percent CCL4 positive cells was assessed from a scale of 0 to 5 as described in Supplemental Table 1. A, Osteoblasts and mesenchymal cells; B, Fibroblasts; C, Proliferative chondrocytes; and D, Hypertrophic chondrocytes. Significance was determined by Kruskal-Wallis one-way analysis of variance. * Indicates significant difference between normal and diabetic groups $(\mathrm{p}<0.05)$. ** Indicates significant differences between 16-day diabetic and diabetic pegsunercept treated groups $(\mathrm{p}<0.05)$. 

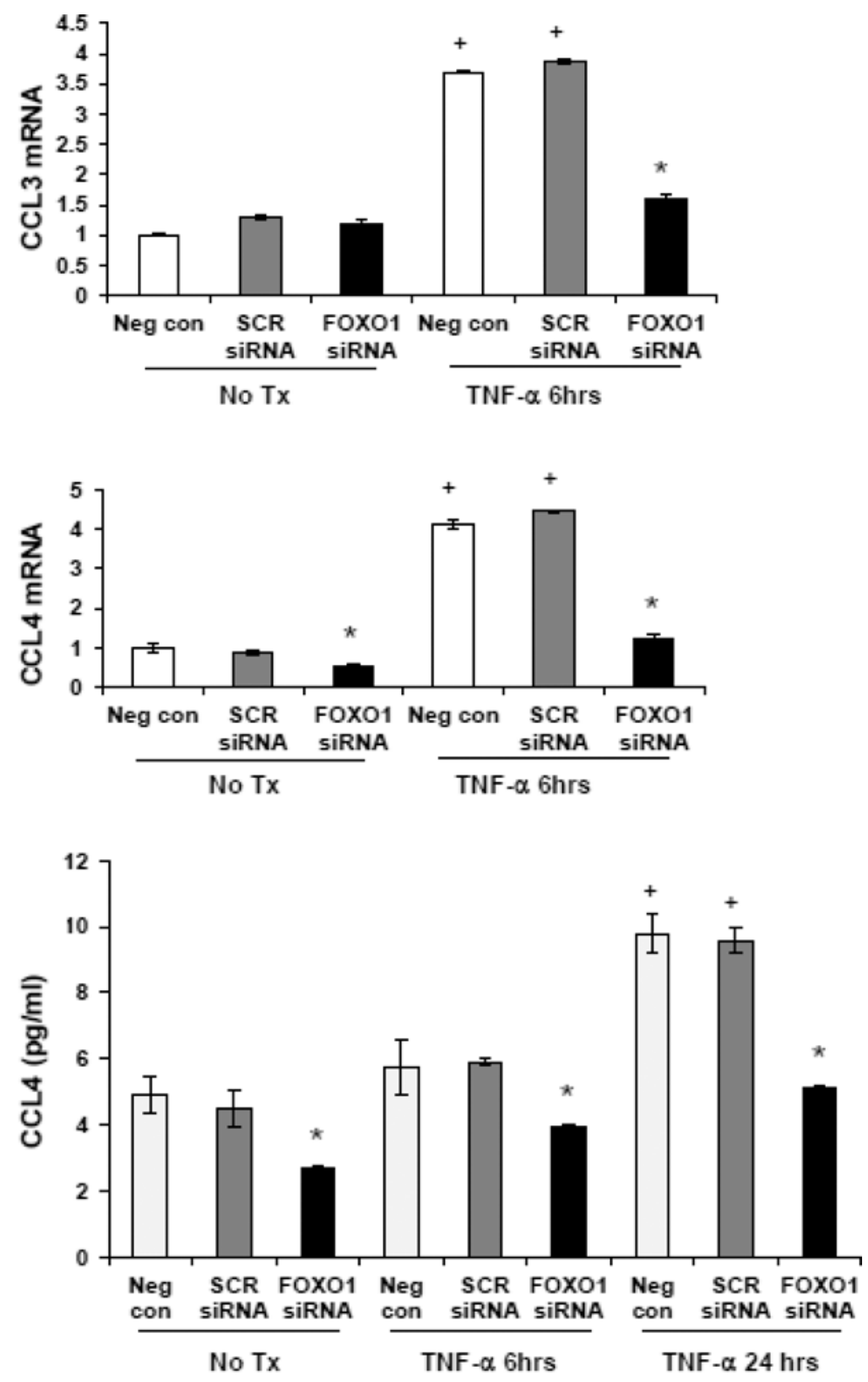

Figure 3. TNF induced CCL4 is FOXO1 dependent in chondrocytes

ATDC5 chondrocytes were transfected with FOXO1 siRNA or scrambled siRNA and stimulated with TNF-a (20ng/ml). mRNA levels of CCL3 or CCL4 were measured by realtime PCR and the protein level of CCL4 was measured by ELISA. mRNA levels are expressed relative to baseline. Data are representative of three independent experiments. + indicates significantly higher than baseline control $(\mathrm{P}<0.05)$; *indicates a significantly less than matched scrambled siRNA $(\mathrm{P}<0.05)$. 

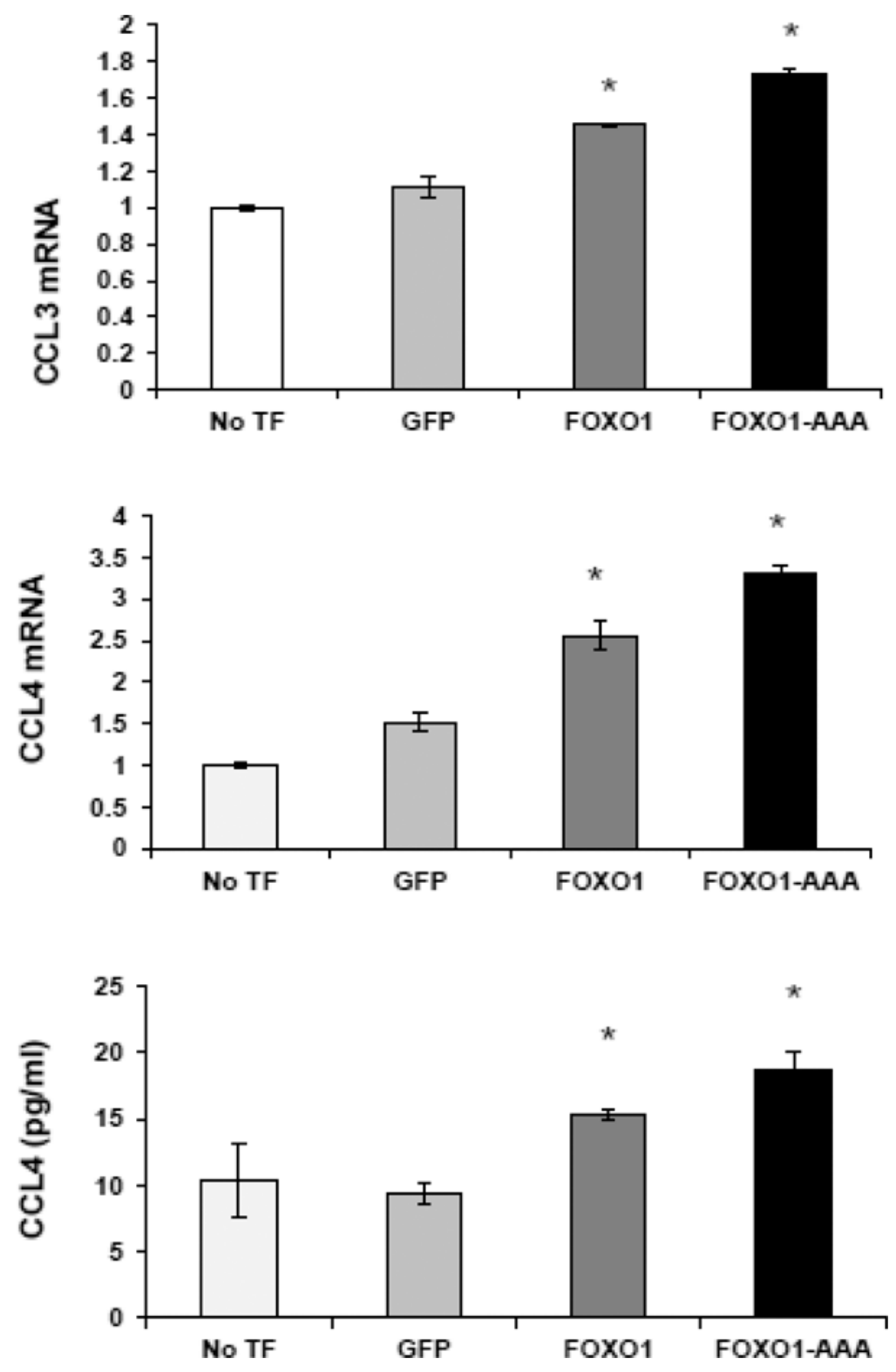

Figure 4. FOXO1 over-expression induces CCL3 and CCL4 in chondrocytes

ATDC5 cells were transfected with constructs containing GFP (negative control), FOXO1 or constitutively active FOXO1AAA. Cell lysates were examined for mRNA levels of CCL3 or CCL4 by real-time PCR and the protein level of CCL4 was measured by ELISA. Data are representative of two or three independent experiments. * indicates significantly higher than GFP negative control $(\mathrm{P}<0.05)$. 


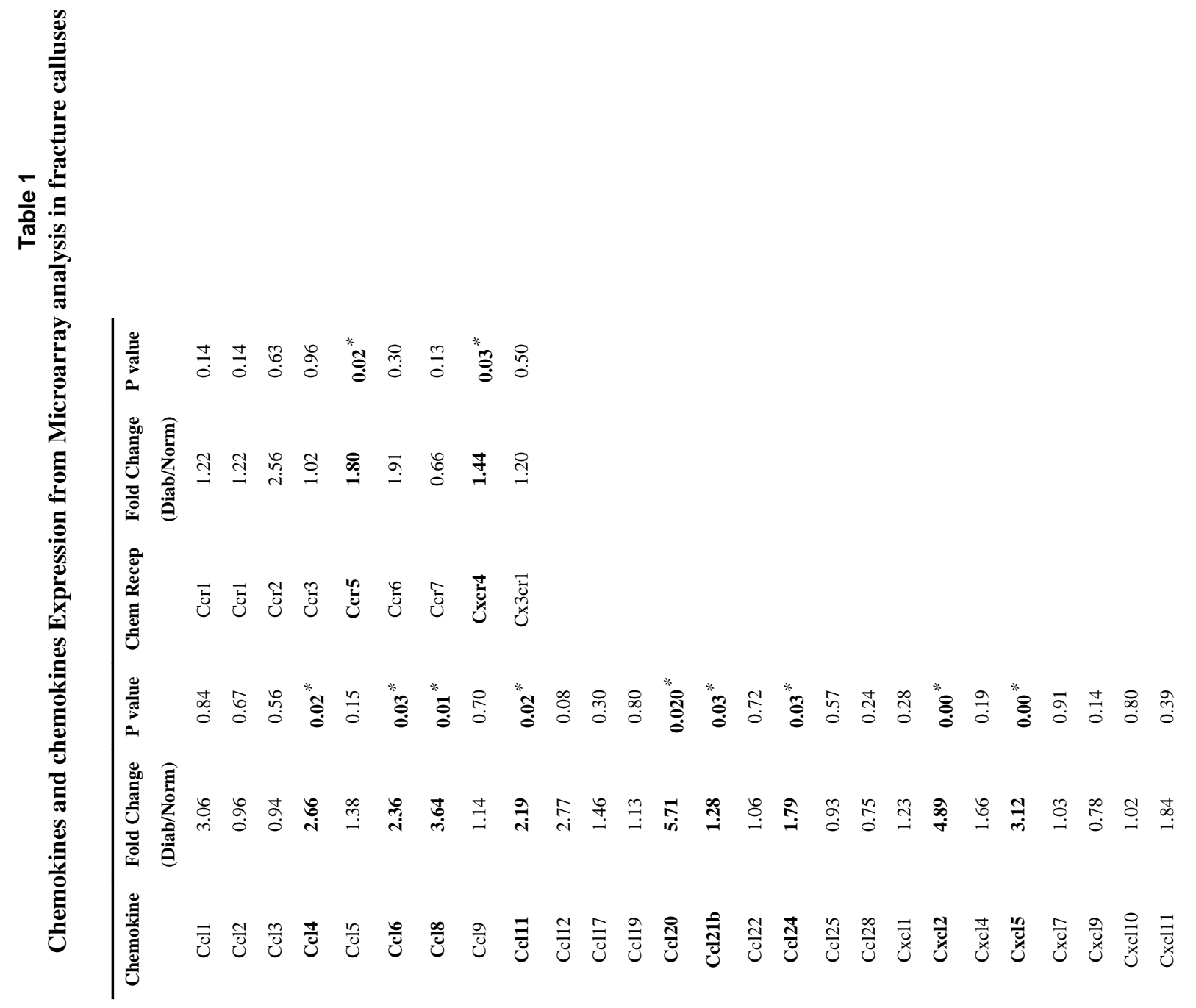


Alblowi et al.

Page 15

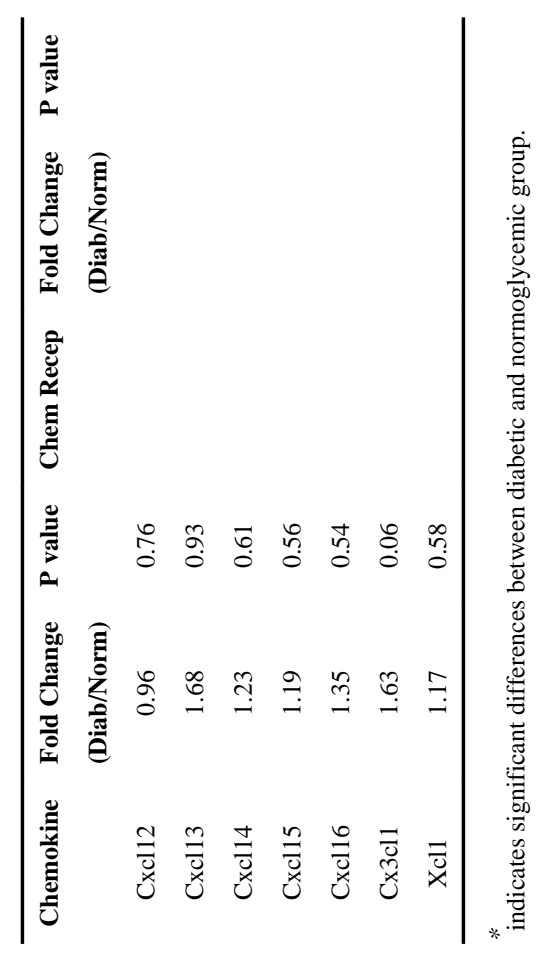

Bone. Author manuscript; available in PMC 2014 March 01. 
Table 2 A

Chemokines and Receptors Gene Expression from PCR Focused Microarray in ATDC5 cells with hypertrophic chondrocytes

\begin{tabular}{|c|c|c|c|c|}
\hline \multirow[b]{2}{*}{ Chemokine } & \multicolumn{2}{|c|}{ TNF-a Treatment } & \multicolumn{2}{|c|}{ FOXO1 knockdown } \\
\hline & Fold Change & $P$ value & Fold Change & $P$ value \\
\hline Ccl1 & 6.13 & 0.04 & 0.19 & 0.05 \\
\hline Ccl2 & $>1000$ & 0.02 & 0.05 & $\mathbf{0}$ \\
\hline Ccl4 & 29.6 & 0.05 & 0.03 & $\mathbf{0}$ \\
\hline Ccl5 & $>1000$ & 0.04 & 0.02 & $\mathbf{0}$ \\
\hline Cc16 & 0.94 & 0.99 & 0.06 & 0.02 \\
\hline Ccl7 & 95.4 & $\mathbf{0}$ & 0.04 & $\mathbf{0}$ \\
\hline Ccl8 & 12.44 & $\mathbf{0}$ & 0.29 & $\mathbf{0}$ \\
\hline Ccl9 & 212.2 & $\mathbf{0}$ & 0.04 & $\mathbf{0}$ \\
\hline Ccl11 & 5.86 & 0.3 & 0.24 & 0.2 \\
\hline $\mathrm{Ccl12}$ & 0.15 & 0.49 & 2.5 & 0.4 \\
\hline Ccl17 & 59.28 & $\mathbf{0}$ & 0.07 & $\mathbf{0}$ \\
\hline Ccl19 & 0.37 & 0.78 & 0.25 & 0.43 \\
\hline Ccl20 & $>1000$ & $\mathbf{0}$ & 0.03 & $\mathbf{0}$ \\
\hline Cxcl1 & 12.55 & 0.02 & 0.3 & $\mathbf{0}$ \\
\hline Cxcl2 & 48.74 & $\mathbf{0}$ & 0.11 & $\mathbf{0}$ \\
\hline Cxcl5 & 11.34 & $\mathbf{0}$ & 0.17 & $\mathbf{0}$ \\
\hline Cxc19 & $>1000$ & $\mathbf{0}$ & $\mathbf{0}$ & $\mathbf{0}$ \\
\hline Cxcl10 & $>1000$ & $\mathbf{0}$ & $<0.001$ & $\mathbf{0}$ \\
\hline Cxcl11 & 82.1 & 0.32 & $<0.001$ & $\mathbf{0}$ \\
\hline Cxcl12 & 2.78 & 0.57 & 2.36 & $\mathbf{0}$ \\
\hline Cxcl13 & 88.1 & 0.1 & 1.14 & 0.86 \\
\hline Cxcl15 & 3.31 & 0.56 & 0.13 & 0.06 \\
\hline $\mathrm{Cx} 3 \mathrm{cl} 1$ & 724.28 & 0.08 & 0.07 & $\mathbf{0}$ \\
\hline Xcl1 & 124.3 & 0.58 & 0.02 & 0.61 \\
\hline Chemokine Receptor & Fold Change & $P$ value & Fold Change & $P$ value \\
\hline Cer1 & 4.46 & 0.05 & 0.23 & 0.05 \\
\hline Ccr2 & 0.83 & 0.9 & 0.99 & 0.99 \\
\hline Ccr3 & 2.31 & 0.54 & 0.2 & 0.03 \\
\hline Ccr 4 & 7.43 & 0.07 & 0.74 & 0.04 \\
\hline Ccr5 & 0.3 & 0.68 & 0.4 & 0.28 \\
\hline Ccr6 & 40.15 & 0.09 & 1.06 & 0.89 \\
\hline Ccr7 & 1.69 & 0.44 & 0.75 & 0.39 \\
\hline Ccr8 & 0.44 & 0.71 & 0.47 & 0.23 \\
\hline Ccr9 & 1.81 & 0.43 & 1.2 & 0.61 \\
\hline Ccr10 & 3.86 & 0.56 & 11.14 & 0.19 \\
\hline Ccrl1 & 0.32 & 0.4 & 2.28 & 0.14 \\
\hline Ccrl2 & 653.19 & $\mathbf{0}$ & 0.01 & $\mathbf{0}$ \\
\hline Ccr111 & 1.35 & 0.8 & 0.85 & 0.89 \\
\hline
\end{tabular}




\begin{tabular}{ccccc}
\hline & \multicolumn{2}{c}{ TNF-a Treatment } & \multicolumn{2}{c}{ FOxO1 knockdown } \\
Chemokine & Fold Change & P value & Fold Change & P value \\
Cxcr3 & 0.95 & 0.99 & 0.7 & 0.61 \\
Cxcr4 & $\mathbf{0 . 5 2}$ & $\mathbf{0}$ & $\mathbf{3 . 3 3}$ & $\mathbf{0}$ \\
Cxcr5 & 4.28 & 0.06 & 0.81 & 0.73 \\
Cxcr6 & 1.35 & 0.28 & 1.22 & 0.07 \\
Cxcr7 & 0.67 & 0.87 & $\mathbf{0 . 5}$ & $\mathbf{0}$ \\
Cx3cr1 & 0.2 & 0.71 & 0.93 & 0.96 \\
\hline
\end{tabular}


Table 2 B

Other Inflammatory Gene Expression from PCR Focused Microarray in ATDC5 cells with hypertrophic chondrocytes

\begin{tabular}{|c|c|c|c|c|}
\hline & \multicolumn{2}{|c|}{ TNF-a Treatment } & \multicolumn{2}{|c|}{ FOXO1 knockdown } \\
\hline & Fold Change & $P$ value & Fold Change & P value \\
\hline TNFa & $>1000$ & 0.00 & $<0.001$ & 0.00 \\
\hline Inhbb & $>1000$ & 0.25 & $<0.001$ & 0.32 \\
\hline Csf1 & 102.28 & 0.15 & 0.16 & 0.00 \\
\hline Nfkb1 & 49.74 & 0.19 & 0.31 & 0.00 \\
\hline $\mathrm{Cmtm} 4$ & 45.88 & 0.24 & 0.78 & 0.03 \\
\hline Bmp10 & 37.51 & 0.02 & $\mathbf{0 . 0 3}$ & 0.01 \\
\hline Hif1a & 24.80 & 0.35 & 0.95 & 0.70 \\
\hline Il1a & 23.53 & 0.00 & 0.18 & 0.00 \\
\hline Lif & 17.85 & 0.42 & 0.67 & 0.89 \\
\hline Tnfrsfla & 14.70 & 0.31 & 0.98 & 0.79 \\
\hline Tlr4 & 14.10 & 0.26 & 1.07 & 0.82 \\
\hline Ppbp & 13.78 & 0.30 & 0.70 & 0.00 \\
\hline Il18 & 11.77 & 0.13 & 0.77 & 0.00 \\
\hline Tnfsf14 & 7.88 & 0.18 & 0.16 & 0.23 \\
\hline Cmtm6 & 6.02 & 0.03 & 0.59 & 0.00 \\
\hline Bdnf & 5.66 & 0.18 & 0.64 & 0.04 \\
\hline Csf2 & 5.09 & 0.62 & 0.29 & 0.00 \\
\hline Mmp2 & 3.46 & 0.12 & 1.10 & 0.47 \\
\hline Il13 & 3.39 & 0.37 & 1.49 & 0.62 \\
\hline Rgs3 & 2.81 & 0.10 & 0.56 & 0.46 \\
\hline $\mathrm{I} 14$ & 2.77 & 0.32 & 1.46 & 0.44 \\
\hline Bmp6 & 1.83 & 0.36 & 0.75 & 0.12 \\
\hline Myd88 & 1.51 & 0.78 & 0.32 & 0.00 \\
\hline Il8ra & 1.47 & 0.29 & 2.09 & 0.19 \\
\hline Inha & 1.27 & 0.77 & 3.36 & 0.00 \\
\hline Tymp & 1.21 & 0.16 & 1.94 & 0.01 \\
\hline $\mathrm{Cmtm} 3$ & 1.09 & 0.90 & 0.96 & 0.66 \\
\hline Cmklr1 & 0.88 & 0.91 & 1.59 & 0.04 \\
\hline Il8rb & 0.50 & 0.83 & 0.15 & 0.09 \\
\hline Trem1 & 0.39 & 0.41 & 1.48 & 0.63 \\
\hline Agtrl1 & 0.22 & 0.68 & 0.35 & 0.43 \\
\hline Bmp15 & 0.18 & 0.31 & 4.48 & 0.08 \\
\hline Ccbp2 & 0.18 & 0.09 & 3.74 & 0.17 \\
\hline Pf4 & 0.16 & 0.63 & 0.52 & 0.13 \\
\hline Gdf5 & 0.11 & 0.23 & 8.19 & 0.08 \\
\hline Cmtm5 & 0.05 & 0.45 & 1.48 & 0.63 \\
\hline Gpr81 & 0.05 & 0.53 & 0.54 & 0.47 \\
\hline Il16 & 0.05 & 0.41 & 0.56 & 0.64 \\
\hline
\end{tabular}




\begin{tabular}{lcccc}
\hline & \multicolumn{2}{c}{ TNF-a Treatment } & \multicolumn{2}{c}{ FOXO1 knockdown } \\
& Fold Change & P value & Fold Change & P value \\
Slit2 & 0.05 & 0.41 & 0.82 & 0.47 \\
Ltb4r2 & 0.03 & 0.32 & 2.38 & 0.03 \\
Cmtm2a & 0.02 & 0.24 & 0.64 & 0.64 \\
\hline
\end{tabular}

ATDC5 cells were transfected with FOXO1siRNA or scrambled siRNA and stimulated with TNF- $a$ as for 6 hour. The TNF- $\mathbf{a}$ treatment columns give the mRNA values for cells incubated with TNF-a plus scrambled siRNA divided by the value for scrambled siRNA and the $\mathrm{p}$ values

calculated for these two groups. FOXO1 knockdown columns give the mRNA values for cells incubated with TNF-a plus FOXO1 siRNA divided by the value for TNF- $a$ plus scrambled siRNA and the $\mathrm{p}$ values calculated for these two groups. Bolded results represent changes where there was at least 1.7 fold increase or 0.7 fold decrease and were statistically significant ( $\mathrm{P} \unlhd$ ).05). 